\title{
On D-pronouns and the Movement of Topic Features
}

\author{
Eric Hoekstra
}

\section{Introduction ${ }^{1}$}

This explorative article deals with the distribution of topic pronouns in Dutch. It is argued that the behaviour of such pronouns is not predicted by theories incorporating the generalisation that a pronoun is free in the clause in which it occurs. The topic pronoun must instead be free in the matrix sentence. We derive these facts from the assumption that the topic pronoun is moved to the beginning of the matrix sentence in LF. We then go on to characterise the set of positions in which antecedents for topic pronouns are found. These positions, it is suggested, function as escape hatches for topic features, in which they can access the larger structure in which sentences are integrated.

\section{Where topic pronouns differ from ordinary pronouns}

\subsection{Basics}

A typical marker of spoken language in Dutch and Dutch dialects is the topic pronoun dat or die 'that'. This pronoun tends to be absent in written language whereas it is abundantly present in spoken language. Consider for example the following sentences (where a topic pronoun is glossed as "TP"):

(1) a. De minister wist er van the minister knew it about "The minister knew about it."

b. De minister die wist er van the minister TP knew it about "The minister knew about it."

These two sentences differ minimally in that the subject de minister is doubled by the topic pronoun die in the (b)-sentence but not in the (a)-sentence. The 
topic pronoun die is logically superfluous but that does not mean it does not have a grammatical function (De Vries 1910-1912). The (b)-sentence would not be used in written language, nor in formal spoken language. The (a)-sentence, on the other hand, is used in either spoken or written language. I will refer to the constituent doubled by the topic pronoun as a dislocated constituent. Notice that there is normally not a prosodic break between the dislocated constituent and the topic pronoun.

The morphological paradigm of topic pronouns is identical to that of demonstrative pronouns used for non-proximate reference. It is quite simple, as given below:

(2) Singular

PLURAL

Non-neuter

Neuter

die 'that'

dat 'that'

die 'those'

As demonstratives, die is used with nouns taking the definite article de (non-neuter nouns) and dat is used with nouns taking the definite article het (neuter nouns). ${ }^{2}$ Non-neuter and plural have fallen together, not only in this case, but also in the case of proximate demonstrative pronouns, definite articles and adjective inflection. It must also be mentioned that the neuter demonstrative pronoun dat is homophonous to the complementiser ("that"), as in English.

There are also topic pronouns for time and place adverbials and for conditional clauses:

(3) a. Morgen dan kom ik bij je langs tomorrow TP:then come I at you along

"Tomorrow, I'll visit you."

b. Gisteren toen kwam ik bij je langs yesterday TP:then come I at you along "Yesterday, I'll visit you."

c. In Den Haag daar wil ik graag wonen in The Hague TP:there would I indeed live "In The Hague, I would like to live."

d. Als 1 en 13 is dan heb je misschien gelijk if 1 and 13 equals TP:then have you maybe right "If 1 and 1 equal 3 then you could be right."

The topic pronoun for conditional clauses is identical to the topic pronoun for time adverbials. Topic pronouns all begin with a D- in Dutch, with the exception of the past tense topic pronoun toen 'then'. ${ }^{3}$ I will in this study be mostly concerned with topic pronouns for DP. Both the term topic pronoun and the term $\mathrm{D}$-pronoun are used in this study.

\subsection{Surprises}

The behaviour of topic pronouns is not predicted by condition B of the Binding theory nor by principles designed to replace it, such as Reinhart's $(1981,1983)$ 
pragmatic principle. The reason is simple: most theories are designed to capture the behaviour of "normal" pronouns. Normal pronouns obey the generalisation that they are free in the clause in which they occur, and may be bound outside. Topic pronouns simply behave different, and thus the behaviour of topic pronouns is not predicted by any theory incorporating the generalisation that pronouns are free in the clause in which they occur. We will now go on to present some facts, in which topic pronouns are contrasted with normal pronouns. To begin, consider the following (judgments reflecting spoken language, not written language where D-pronouns are taboo):

(4) a. Marie zei tegen Piet $_{\mathrm{i}}$ [dat ik hem ${ }_{\mathrm{i}} /$ die $_{\mathrm{i}}$ niet mag] Marie told to Piet that I him/TP not like "Marie told Piet that I did not like him."

b. Marie $e_{i}$ zei tegen Piet $_{i}$ [dat ik haar ${ }_{i} /{ }^{*}$ die $_{i}$ niet mag] Marie told to Piet that I her/TP not like "Marie told Piet that I did not like her."

c. $\operatorname{Jan}_{\mathrm{i}}$ vond het huis [dat ze hemi $/ * \mathrm{die}_{\mathrm{i}}$ wilden verkopen] niet mooi Jan found the house that they him/TP wanted sell not nice "Jan did not like the house which they wanted to sell him."

d. D-pronoun domain generalisation

A D-pronoun is free in the domain of the matrix sentence in which it occurs (not just the clause)

The domain in which pronouns must be free according to condition B and other theories incorporating the clause generalisation is bracketed in the examples above. The observation is that D-pronouns must be free is a much larger domain than just the clause in which they occur. In the (c) sentence the D-pronoun is separated from its antecedent by two clause boundaries and a DP boundary, yet coreference is excluded. The tentative generalisation is given in (d).

The notion "free" is normally defined in terms of the c-command:

(5) $\mathrm{A}$ is free from $\mathrm{B}$ iff $\mathrm{B}$ does not c-command $\mathrm{A}$, where $\mathrm{A}$ is coindexed with $\mathrm{B}$.

The examples above are problematic for the definition of the syntactic domain in which condition B applies but they are not problematic for the application of the notion c-command to these examples.

\subsection{Proposal}

To account for these facts, we can stipulate a different domain definition for topic pronouns. This covers the facts, but it does not buy us anything else. Instead, I would like to propose a change in the conceptual definition of condition $\mathrm{B}$, which automatically predicts different binding domains for topic pronouns and ordinary pronouns. 
The idea is based on the minimalist insight (Chomsky 1995) that if a process is overt is one language (feature $\mathrm{F}$ is strong and therefore it triggers movement before $\mathrm{PF}$ ), it must be covert in another (feature $\mathrm{F}$ is weak and therefore it does not trigger movement until LF). After all, this is the essence of the Minimalist program. Now, pronouns are moved in $\mathrm{PF}$ in some languages into the functiona1 domain as clitics. If they are not moved in PF they must be moved in LF. Therefore we claim, by theory-internal reasoning, that the following holds:

(6) Pronoun Movement Hypothesis (follows from Minimalist Program)

All languages create pronominal clusters in the functional domain in LF.

What is important is that pronouns, under this proposal, must move outside the domain of thematic position. This will derive a configuration where even the pronoun coindexed with the lowest (in terms of c-command) theta-role crosses the theta position of the highest pronoun:

(7) Pronominal cluster (P:1 .. P:n) ... Th-pos:1 .. Th-pos:n

where $1 \ldots \mathrm{n}$ is used to represent binding,

where the pronominal cluster c-commands Th-pos:1,

Th-pos: 1 c-commands Th-pos:2, and so on

We thus assume that a clitic cluster is in LF always higher (in terms of c-command) than the domain in which a verb discharges its theta roles: this is a feature of most, if not all, analysis of clitic clusters.

Every pronoun in the cluster in (7) must be able to bind its trace in theta position. The consequences of this are given in (8):

(8) Consequence of the Pronoun Movement Hypothesis

If a pronoun is coreferential with another argument in the domain of its chain, that pronoun will bind two th-positions, thus have two theta roles.

(9) Theta Criterion: a chain may not have two or more th-roles

(10) Consequence of Pronoun Movement and Theta Criterion

A pronoun may not be coreferential with another argument in the domain defined by its movement chain

A relevant instantiation of $(10)$ is that a pronoun may not be coreferential with another argument of the same verb (the function of reflexives is to circumvent this, for example in the manner proposed by Reinhart \& Reuland (1991)).

We have now derived condition $B$ from the minimalist hypothesis that pronoun clusters are created in LF on the analogy of clitic clusters in PF. Notice that we do not have to formulate condition $\mathrm{B}$ as an independent principle. The clause-boundedness of condition $B$ comes for free as a result of the clause-boundedness of pronoun movement in LF.

We are now in a position to develop a conceptual analysis of the D-pronoun facts. This is given in (11): 
(11) Fact: D-pronouns must be free in a larger domain than ordinary pronouns, namely in the domain of the matrix sentence

(12) Consequence of (10) and (11)

D-pronouns undergo long-distance LF-movement to the beginning of the matrix sentence

Thus we have proposed an account capturing both the binding facts concerning ordinary pronouns and the binding facts concerning D-pronouns in a non-trivial manner, i.e. we do not stipulate the domain in which a pronoun must be free. The size and location of the domain is defined by the chain representing the movement which the pronouns undergo in LF.

\section{Who moves in left-dislocation constructions?}

\subsection{Is the dislocated phrase moved or the topic pronoun?}

Consider a simple case of left-dislocation with topicalisation of the D-pronoun:

(13) Jan die ken ik niet

Jan TP know I not

It might also be suggested (Grohmann 1997) that the dislocated phrase Jan is moved, and that the topic pronoun represents the spelling out of a trace. I will refer to this analysis as the spell-out analysis. I will argue first against a conventional spell-out analysis. On the basis of the arguments presented, I will develop a refined version of the analysis, incorporating insights from the spell-out analysis but avoiding the problems.

\subsection{Arguments against movement of the dislocated phrase}

If the dislocated phrase is what is moved we expect the dislocated phrase to satisfy selection requirements in the base position of the chain. If the topic pronoun is what is moved then we expect the topic pronoun to satisfy selection requirements in the base position of the chain. The two options are schematised below:

(14) a. Dislocated $\mathrm{XP}_{\mathrm{i}} \quad\left[\mathrm{TP}\right.$-pronoun $\ldots\left[\ldots \mathrm{t}_{\mathrm{i}} \ldots\right]$

b. Dislocated XP $\quad\left[\right.$ TP-pronoun $_{\mathrm{i}} \ldots\left[\begin{array}{lll}\ldots & \mathrm{t}_{\mathrm{i}} & \ldots\end{array}\right]$

Of course, the element that moves will have to satisfy the selection criteria downstairs. Thus the analysis in (a) predicts that the dislocated XP will satisfy selection criteria downstairs. The (b) analysis predicts that the topic pronoun satisfies selection criteria downstairs. We will now present three cases indicating that the (b) analysis is correct, not the (a) analysis (from Hoekstra \& Zwart 1994). 
Case 1. Consider the following contrast:

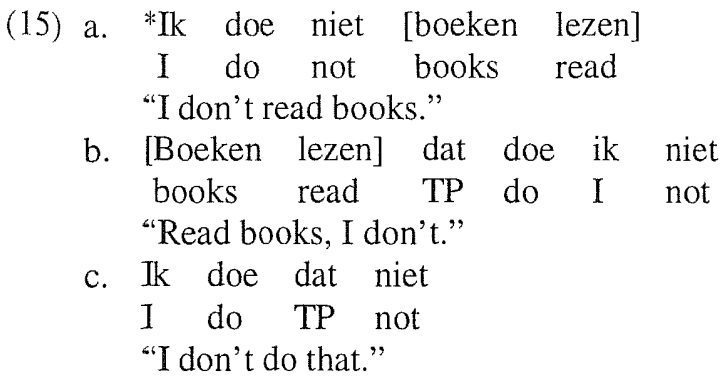

The infinitival IP-constituent boeken lezen 'read books' may not occur as a complement to doen 'do', as the (a)-sentence shows, because this verb does not categorially select infinitival IP. If boeken lezen 'read books' occurs as a left-dislocated constituent at the periphery of the clause, however, and is doubled by a topic pronoun, the structure is fine. These facts are explained if it is the topic pronoun which moves, after it has satisfied the selection criteria downstairs. The dislocated phrase cannot have been moved because it violates the selection criteria downstairs, as indicated in (a).

Case 2. A comparable example comes from Frisian. The verb wenje 'to live (somewhere)' requires a PP complement, but a dislocated phrase may have the form of a DP (Hoekstra 1995):

(16) a. Reduzem dêr woe ik wol wenje

Reduzem TP:there would I sure live

"In Reduzem, I sure would like to live."

b. *Ik woe wol Reduzem wenje

I would sure Reduzem live

"I sure would like to live in Reduzem."

c. Ik woe wol dêr wenje

I would sure there live

"I sure would like to live there."

If the dislocated phrase had been moved, it would violate the selection criteria downstairs, as shown by (b), and the sentence (a) would be ungrammatical. If the locative D-pronoun is what moves, it satisfies the selection criteria downstairs, as shown by (c), and (a) is grammatical, as expected.

It could be argued that these examples involve so-called "hanging topic" (HT) constructions. HT constructions in German (Grohmann 1997) have the following properties (in the gloss REFL stands for "reflexive"):

(17) a. The dislocated XP cannot be bound into.

b. The dislocated XP does not Case-agree with the topic-pronoun. 
(18) a. *[Der Wagen von sich] den hat er verkauft

the car of REFL TP has he sold

"His car, he sold."

b. [Den Wagen von sich] den hat er verkauft

the car of REFL TP has he sold

"His car, he sold."

The (a) sentence shows that a HT-construction cannot be bound into and does not case-agree with the topic pronoun. The (b) sentence illustrates a non-HT construction, according to Grohmann. In Dutch, case is not visible on DP but we can apply the binding test to see whether the examples discussed by us are HT-constructions.

Consider the following sentences, in which the dislocated element violates selection criteria, yet binding into it is allowed:

(19) a. $\left[\text { Elkaar }_{j} \text { helpen }\right]_{i}$ dat doen $z_{j}$ hier niet $t_{i}$ each other help TP do they here not "Help each other, they don't do that here."

b. [Syn $n_{j}$ berteplak] dêr $r_{j}$ soe elkenien $n_{j}$ wol $t_{i}$ wenje wolle his birth place there would everybody sure live want "Everybody would sure like to live in the place of his birth."

(20) a. *Ze doen hier niet elkaar helpen they do here not each other help

"They don't help each other here."

b. *Elkenien soe wol syn berteplak wenje wolle everybody would sure his birth place live like "Everybody sure would like to live in the place of his birth."

(21) a. Ze doen dat niet they do that not "They don't do that."

b. Elkenien soe wol dêr wenje wolle everybody would sure TP:there live like "Everybody sure would like to live there."

Binding is possible; hence the counterexamples presented here cannot be explained away as involving HT-constructions.

\subsection{The paradox}

We now have an apparent paradox: the facts we presented indicated that the topic pronoun satisfies the selection criteria downstairs. Nevertheless, the dislocated constituent may be bound into. Although an account of reconstruction and binding is beyond the scope of this paper, we would like to point out that Grohmann's assumption that binding requires reconstruction to a simple c-command configuration might be mistaken. To illustrate, consider the following: 
(21) c. [What they $y_{i}$ did] was eat each other' $s_{i}$ sandwiches

d. [Every farmer who owns a donkey $y_{i}$ ] loves $i t_{i}$

In both cases there is no way in which reconstruction can apply so as to bring the antecedent in a c-commanding position. The examples make clear that the binding mechanism may work in intricate ways. A full treatment of binding and reconstruction falls outside the scope of this paper.

Earlier we argued that pronouns must be free in the domain of their chains, and that topic pronouns move to the beginning of the matrix sentence in LF. However, we also observe that a topic pronoun can coindex with a leftdislocated constituent:

(22) a. Jan die ken ik niet

Jan TP know I not

"Jan I don't know."

b. Ken je Jan? Die ken ik niet

know you Jan TP know I not

"Do you know Jan? I don't know him."

If our account is correct, then we are bound to conclude that the dislocated phrase in the (a) sentence is outside the domain defined by the chain of the topic pronoun (as is evident in the case in the (b) example). This means that a movement analysis for the dislocated element itself is out of the question. We arrived at the same conclusion on the basis of the facts concerning selection criteria.

Coindexation between the left-dislocated element and the topic pronoun is not a relation between members of a chain, but it is a relation between two chains. This is immediately clear from the (b) sentence. If we want to generalise over both cases, we must conclude that the (a) sentence also involves two chains.

The relation between the two chains could either be coreference (cf. Heim 1982) or chain composition (the latter operates in parasitic gaps). A test for coreference since Reinhart (1983 and elsewhere) is that strong quantifiers cannot corefer. This test is applied to German data by Grohmann (1997:15), and the same facts are valid for Dutch:

(23) a. *Niemanden den hat sie geküßt (German) nobody TP has she kissed

b. *Niemand die heeft ze gekust (Dutch) nobody TP has she kissed

(24) a. Sie hat niemanden geküßt

(German)

she has nobody kissed

b. Ze heeft niemand gekust

she has nobody kissed

(Dutch)

The failure of D-pronouns to corefer with strong quantifiers is an indication that coreference, in some sense, is involved, a weaker concept than binding. 
Chain composition, on the other hand, is what relates a parasitic chain to a non-parasitic chain (Chomsky 1982). The defining characteristic is that the parasitic chain is A-free from the chain on which it parasitises (where " $\mathrm{e}$ " stands for the parasitic gap):

(25) a. Who did [a friend of $\mathrm{e}_{\mathrm{i}}$ ] please $\mathrm{t}_{\mathrm{i}}$

b. *Who $t_{i}$ pleased [a friend of $e_{i}$ ]

(26) a. Who $\mathrm{O}_{\mathrm{i}}$ did you phone [without talking to $\mathrm{e}_{\mathrm{i}}$ ]

b. *Who was phoned up [without talking to $\mathrm{e}_{\mathrm{i}}$ ]

In the (a) examples, the parasitic position, indicated by "e" is A-free from the non-parasitic chain. In the (b)-examples, " $\mathrm{e}$ " is c-commanded by the trace in A-position, hence A-bound.

We could consider chain composition to be the formalisation of coreference. We can extend the concept of chain composition so as to apply to the relation between a dislocated phrase and a topic pronoun on the assumption below:

(27) The dislocated phrase is not in an A-position.

If (27) holds, chain composition can apply to express coreference between the dislocated phrase and the topic pronoun.

(27) is not implausible, by the following argument. An A-position is an A-position by virtue of being linked up to a predicate, either by means of case or by means of theta role. A left-dislocated constituent, being base-generated, is not linked up to any predicate. Therefore it is not implausible to suppose that left-dislocated elements can undergo chain composition with the topic pronoun. Below we will suggest that the topic pronoun is related to its antecedent by means of movement of zero topic features.

\section{Topic pronouns and the positions in which their antecedents are found}

\subsection{Textual structure and the operations "move" and "merge"}

It was argued above that topic pronouns must be free in the matrix sentence in which they occur. The question therefore arises:

(28) Where does a topic pronoun find its antecedent?

Normal syntactic principles apply within the clause, or within the sentence but we have not explored the question whether they apply outside the sentence. One thing is clear: it cannot be the case that matrix sentences exist in isolation, that they are not part of a larger, say textual structure.

The theoretical interest of topic pronouns is that they both have a function within the sentence and outside, as a means of connecting up sentences. Thus they raise the issue of how sentences connect up with each other and are integrated into a coherent and structured whole, the textual structure. It cannot be doubted that sentences are fused into larger units. Hoeksema \& Napoli (1993) 
discuss an interesting construction which can either be expressed as one sentence or as two:

(29) a. The sun was so hot (that) I fainted.

b. I fainted, the sun was so hot.

In the (a)-sentence, so links up two clauses. In the (b)-sentence, so links up two sentences. As a result, bound variable binding is possible in the (a)-type sentence but not in the (b)-type, as shown below:

(30) a. Nobody was so hot (that) he fainted.

b. *Nobody fainted, he was so hot.

The sentence boundary in the (b) sentence blocks bound variable binding. The meaning of (a) is very similar to that of (b). Hence the two sentences in (b) and the two clauses in (a) must ultimately receive very similar semantic representations. Within the Minimalist Program, parts of sentences are integrated in the structural representation of the sentence by means of the operations "merge" and "move". The question, how are sentences integrated into a larger structure, translates into the Minimalist Program as follows: does the creation of textual structure also take place by means of the operations "merge" and "move"? If not, how can we express the relation between (29a) and (29b)? Furthermore, we can ask ourselves the question: which syntactic processes occurring within the sentence can apply between sentences? The answer is none: most processes are clause-bound, and therefore, sentence-bound, given that a sentence-boundary is an even stricter boundary than a clause boundary. Even processes that appears to cross clause-boundaries, like wh-movement or bound variable binding, cannot cross sentence-boundaries. This is shown below:

(31) a. $\mathrm{Who}_{i}$ do you think [that we saw $\mathrm{t}_{\mathrm{i}}$ ]

b. Nobody $y_{i}$ thinks [that he ${ }_{i}$ will win]

(32) a. *Who was it bad luck. You consider $t_{i}$ responsible for it?

"It was bad luck. Who do you consider responsible for it?"

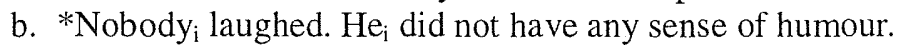

"Nobody laughed. They did not have any sense of humour."

The relation between a topic pronoun and its antecedent, coreference or chain composition, is able to cross sentences, as shown by (22b) repeated as (33):

(33) Ken je $\operatorname{Jan}_{\mathrm{i}}$ ? Die $\mathrm{Di}_{\mathrm{i}}$ ken ik niet.

know you Jan TP know I not

"Do you know Jan? I don't know him."

The answer to the question of where D-pronouns find their antecedent must therefore be: in a larger structure, call it the textual structure. If coreference plays an important part in this process then coreference is of more interest than we might think. Topic pronouns also play a role in the sentence. Thus topic pronouns might provide insight into the way sentences are integrated into larger 
structures. The human mind does not deal with sentences in isolation, it places them in a larger structure. Topic pronouns may thus ultimately provide insight into the way in which the human mind structures text. I will go on to argue that the relation between a topic pronoun and a dislocated XP is not subject to island constraints, because the relation is in part created at the higher structural level of the text, rather than at the level of the sentence.

\subsection{Island violations}

Consider the following German example from Grohmann (1997), used by him to illustrate the claim that left-dislocation violates island constraints:

(34) [Diesen Frosch $]_{i}$ fragt sich der Bauer, ob der König den $n_{i}$ mag this frog asks himself the farmer whether the king TP likes "This frog, the farmer wonders whether the king likes him."

Grohmann assumes that the dislocated element has been moved, and that the topic pronoun was the spell-out of a trace. Hence this constituted an island violation. For us, the island violation is in LF, since in LF the D-pronoun will move to the front of the matrix sentence.

The problem is clear: topic pronouns cannot be moved to the beginning of the sentence without violating island constraints (both under our analysis and under Grohmann's). The problem is reminiscent of the problem of Wh-movement in the seventies: nearly all syntactic processes (passivisation, agreement) are clause-bound, yet Wh-movement is not. The problem has been solved by means of successive-cyclic movement through licensed escape-hatches. The definition of escape hatches depends on the version of the theory (barriers, licensed position), the insight is the same.

The problem posed by topics is of the same nature, and I would solve it in a similar manner: by the postulation of an escape hatch for topic features, making it possible for the XP-topic pronoun relation to apparently violate movement constraints. The landing site of the pronominal topic features must be an appropriately licensed position, that is, a topic position. My claim is that the position of the topic "diesen Frosch" is licensed in the sentence above by the bridge verb "fragen". The assumption is that only bridge verbs can license topic positions (like only bridge verbs can license escape hatches for successive-cyclic movement).

The first argument for this claim is semantic. When you "ask something", you ask something about something else. This "about something else" is a topic position licensed as an argument of the verb. Thus it makes sense semantically, to suppose that bridge verbs like "think", "say" and so on have a topic position as part of their array of arguments.

Second argument. If the topic is part of the argument structure of the matrix verb, then it is at least possible that the matrix verb may impose some formal 
selection restrictions. In German, this is not visible, since the topic takes along its case from its trace position. In Dutch, however, the topic must receive its case from the matrix verb, in the form of a preposition, a literal translation from German, as in (a) being ungrammatical (in the gloss PTC stands for "particle"):

(35) a. *Deze kikker ${ }_{i}$ vraagt de boer zich af $\ldots$

this frog asks the farmer himself PTC ...

$\ldots$ of de koning die $e_{i}$ mag

... whether the king TP likes

"This frog, the farmer wonders whether the king likes him."

b. Van deze kikker ${ }_{i}$ vraagt de boer zich af $\ldots$ of this frog asks the farmer himself PTC ...

$\ldots$ of de koning die $_{i}$ mag

... whether the king TP likes

"This frog, the farmer wonders whether the king likes him."

I will refer to the van-phrase as the about-argument or the about-PP. Under a traditional movement analysis the preposition van would have to be inserted. It is possible, but not enlightening. The analysis proposed here is that topic features move from the topic pronoun die to the "about" PP, van deze kikker.

The fact that only topics allow long distance dependencies ties in nicely with the fact that topics typically play a role not only at the clause level but also above the clause level.

Since we do not move the about PP itself but topic features of the topic pronoun, we predict that the topic pronoun must satisfy categorial selection requirements. This is correct:

(36) a. Ik vind van boeken lezen niet dat Jan dat doen moet

I find of books reading not that Jan TP:that do must

"I don't think that Jan should read books."

b. *Ik vind niet dat Jan boeken lezen doen moet

I find not that Jan books reading do should

"I don't think that Jan should read books."

(37) a. *Ik vind van boeken lezen niet ...

I find of books reading not ...

... dat mensen Jan dat moeten zien doen

... that people Jan TP:that must see do

"I don't think that people should see Jan reading a book"

b. Ik vind niet dat mensen Jan boeken moeten zien boeken lezen

I find not that people Jan books must see read

"I don't think that people should see Jan reading a book"

We have evidence both ways. The first pair shows that the topic pronoun satisfies the selection requirements in the (a) sentence, not the topic antecedent. The second pair shows that the topic pronoun fails to satisfy the selection require- 
ments in the (a) sentence. The same observation were made for simple left dislocation constructions, in (15-16).

The problem with selection criteria disappears if we assume that movement targets not the topic pronoun itself but zero topic features on the topic pronoun. The pronoun satisfies or fails to satisfy the selection requirements downstairs.

Perhaps the strongest argument for our analysis is that a bridge verb is indispensable for licensing island violations. The German example in (34) and the Dutch examples following it typically involve bridge verbs. If there is no bridge verb, no island violations are possible, as shown below:

(38) a. *Jan regent het zodat ik die nat zie worden

Jan rains it so that I TP wet see become

b. Het regent zodat ik Jan nat zie worden

It rains so that I Jan wet see become

"It rains so that I see Jan become wet."

Regenen does not select an about-constituent. However, we can also introduce such a constituent by means of sentence adverbials, and thus create a landing site for topic features:

(39) Wat Jan betreft, het regent zodat ik die nat zie worden As Jan concerns it rains so that I TP wet see become "As for John, it rains so that I see him become wet."

Bridge verbs thus provide appropriate escape hatches for the topic features of the topic pronoun. The idea of escape hatches is anyhow necessary for Wh-items: there is no reason why only Wh-items should have escape hatches. Spell-out problems are avoided by moving empty topic features. Those features find their antecedent in an escape hatch, just like wh-features do.

\subsection{Antecedents for D-pronouns}

We had proposed earlier that a D-pronoun is free in the domain of its chain, and we identified the matrix sentence as that domain. The question is now: where does a D-pronoun find its antecedent? Its antecedent must be in a position where topic features are licensed. Antecedents for D-pronouns can be found in the following positions, escape hatches for topic features:

(40) a. As an "about" argument to bridge verbs

b. In a preceding sentence

c. As a left-dislocated constituent

d. In an adverbial constituent of the type "with respect to X"

e. Parenthetical

f. dat-iteration construction

The latter two environments have not yet been discussed. We will first discuss parentheticals. The antecedent for a $\mathrm{D}$-pronoun can also be in the other half of a parenthetical construction: 
(41) Weet jij of die, Jan, meegaat know you whether TP, Jan, comes along?

"Do you know whether Jan comes along?"

The antecedent for a D-pronoun can also be the constituent sandwiched between two complementisers in a dat-iteration construction (see Hoekstra 1992). The relevant construction has received little attention in the literature, because it only occurs in spoken language. If asked, linguists claim it is a processing quirk, like repititions, stuttering and so on. If that were correct then we would expect the same phenomenon to show up in other languages, like English. But in English it is systematically absent. The fact that languages differ with respect to this phenomenon suggests it is grammatical in nature. The relevant construction is given below:

(42) a. Ik denk dat Jan dat ik die moet vragen

I think that Jan that I TP must ask

"I think that John, I should ask."

b. Ik denk dat morgen dat hij dan al komt

I think that tomorrow that he TP:then already comes

"I think that tomorrow, he'll come already."

c. Ik denk dat in Rome dat hij daar graag wil wonen

I think that in Rome that he TP:there indeed wants live

"I think that in Rome, he would like to live."

(43) a. Ik verbaas me erover dat Jan dat ik die moet vragen

I amaze myself about it that Jan that I TP must ask

"I'm amazed at the fact that John, I should ask."

b. Ik verbaas me erover dat morgen ...

I amaze myself about it that tomorrow ...

... dat hij dan al komt

... that he TP:then already comes

"I'm amazed at the fact that tomorrow, he'll come already."

c. Ik verbaas me erover dat in Rome ...

I amaze myself about it that in Rome ...

... dat hij daar graag wil wonen

... that he there indeed wants live

"I'm amazed at the fact that in Rome, he would like to live."

This construction is sometimes referred to as CP-recursion. This is undesirable for several reasons. $\mathrm{CP}$ is a bona fide syntactic category. If something like $\mathrm{CP}$-recursion on the same lexical head (dat) exists then we would also expect AgP-recursion, VP-recursion, PP-recursion, all with the same lexical item as head. However, there is no AgP-recursion, VP-recursion or PP-recursion on the same head: 
(44) a. *Ik moet moeten voetballen

I must must play-soccer

b. *Ik hoop op een wonder daar op

I hope for a miracle it for

Hence we claim that the sentences above do not involve CP-recursion, but iteration.

The set of positions in which antecedents for topic pronouns are found all have in common that they are on the verge of sentential structure. None of these positions is a regular theta-position, with the possible exception of the argument to a bridge verb. Note though that the bridge verb does not assign a normal theta role to the argument in the "about" phrase. The "about" phrase is not a participant in the action described by the bridge verb like the subject is, nor is the "about" phrase brought about by the action described by the bridge verb. In German, the about-phrase shares morphological case with the topic pronoun. In Dutch, the default preposition van shows up.

We could suggest that the set of environments given above all share the common feature that the positions are all escape hatch positions through which the larger structure in which the sentence occurs is accessed. We could then maintain the claim that topic pronouns are free in the matrix sentence. It would lead us too far afield to try to work out such a proposal.

\section{Concluding Remarks}

In this explorative article the distribution of the topic pronouns die/dat was discussed. It was shown that these pronouns have to be free in the domain of the matrix sentence. It was also shown that they can find their antecedent in a set of positions which we characterised as escape-hatches for topic features. This allowed us to relate a topic pronoun and its antecedent by means of the movement of zero topic features. We will leave it to future research to further develop the idea of viewing movement of topic features as a way of formally characterising the relation of coreference between a topic pronoun and its antecedent.

\section{Address of the Author}

Eric Hoekstra

Frisian Academy

Royal Academy

P.O. Box 54

NL-8900 AB Ljouwert/Leeuwarden (The Netherlands)

\section{Notes}

1 I would like to thank Marjo van Koppen, Jarich Hoekstra and an anonymous reviewer for comments and/or discussion. According to the latter, die in (1b) initiates a new full clause, 
while the coreferential De minister is left-extraposed. I contest this insight on the basis of my native competence of Dutch: (1b) is one single clause just as well as (1a).

2 Prescriptive grammar states that in referring to a het noun, dat must be used, and in referring to a de noun, die. As shown in Romijn (1996), this is not a description of the facts.

3 There is also a possessive topic pronoun diens (see Postma 1984). It is typical of written language. In spoken language an analytic form is used, namely die $z$ ' $n$, which can be glossed as "TP his".

4 The preposition could remain absent in Middle Dutch (Van den Berg 1992), as shown below in (i):

(i) der Walewein claechde sijn swert dat hijt daer niet en hevet the lord Walewein complained his sword that he-it there not has "The lord Walewein complained that he didn't have his sword there."

Thus Middle Dutch resembles German more than Modern Dutch.

\section{References}

Berg, E. van den. 1992. "Zinsvermenging in het Middelnederlands." Taalkundig Bulletin 22, $101-108$.

Chomsky, N. 1982. Some concepts and consequences of the theory of government and binding. Cambridge, Mass.: MIT Press.

Chomsky, N. 1995. The Minimalist Program. Cambridge, Mass.: MIT Press.

Grohmann, K. 1997. "On Left Dislocation." In W. Abraham \& K. Grohmann (eds.), Groninger Arbeiten zur germanistischen Linguistik (GAGL) 40, 1-33.

Heim, I. 1982. The Semantics of definite and indefinite Noun Phrases. New York: Garland.

Hoeksema, J. \& D. J. Napoli. 1993. "Paratactic and subordinative So." Journal of Linguistics 29, 291-314.

Hoekstra, E. 1992. On the Parametrization of Functional Projections in CP. In: A. J. Schafer (ed.), 23th Proceedings of the North-East Linguistic Society 1992. Amherst: University of Massachusetts, 191-204.

Hoekstra, E. \& J.-W. Zwart. 1994. "De Structuur van de CP. Functionele Projecties voor Topics en Vraagwoorden in het Nederlands." Spektator 23, 191-212.

Hoekstra, J. 1995. "Preposition stranding and resumptivity in West-Germanic." In: H. Haider, S. Olsen \& S. Vikner (eds.), Studies in Comparative Germanic Syntax (=Studies in Natural Language and Linguistic Theory, vol. 31). Kluwer, Dordrecht, 95-118.

Postma, G. 1984. "The Dutch pronoun diens; distribution and reference properties." In: H. Bennis \& W.U.S. van Lessen Kloeke (eds.), Linguistics in the Netherlands 1984. Dordrecht: Foris.

Reinhart, T. 1981. "Pragmatics and Linguistics: an Analysis of Sentence Topics." Philosophica $27,53-94$.

Reinhart, T. 1983. Anaphora and Semantic Interpretation. London: Croom Helm.

Reinhart, T. \& E. Reuland. 1991. "Anaphors and Logophors: an Argument Structure Perspective." In J. Koster \& E. Reuland (eds.), Long Distance Anaphora. Cambridge: Cambridge University Press, 183-321.

Romijn, K. 1996. Hoe doen we het? Verwijzen naar linguïstische en cognitieve representaties met het voornaamwoord het. Amsterdam: Publicaties van het Meertensinstituut.

Vries, W. de. 1910-1912. Dysmelie. Opmerkingen over syntaxis. Verhandeling behorende bij het programma van het gymnasium der gemeente Groningen voor het jaar 1910-1911. Idem voor het jaar (vervolg) 1911-1912. Groningen: B. Jacobs. 